\title{
How three high-fee independent secondary schools in the Western Cape currently conceptualise language support for international students with language barriers.
}

\begin{abstract}
A steadily increasing number of wealthy foreigners, mainly from other African countries, opt to send their teenage children to independent secondary schools in South Africa to give their children what they perceive to be the "best education possible" (Spaull, 2015: 14). As is the case globally, international students entering the South African independent school system at secondary level may face major difficulties in acquiring academic English.
\end{abstract}

International students with language barriers tend to gravitate towards schools without rigorous entrance examinations in place. This article focusses on three high-fee independent secondary schools in the Western Cape, two boarding schools and one day school, whose websites in 2017 did not indicate that they had formal, exclusionary entrance examinations in place. Data subsequently provided by these schools showed that their student bodies did, in fact, include a substantial number of international students.

For this study, the principal and two other senior members of staff at each of the three schools were interviewed to ascertain how they provided language support for international students with language barriers. After reporting back on these interviews, the discussion section of the article critically analyses current practices, with the conclusion of the article acting as a preamble for a follow-up article, in which aspects of the CLIL (content and language integrated literacy) model will be identified which could prove useful to these schools to further support students and staff.

Keywords: international students, language support, independent schooling, challenges, secondary schools

\section{Introduction}

Although academics globally have written about refugees on the poor side of the spectrum, comparatively little data seem to exist about so-called 'privileged' migrants moving between borders, mainly for educational purposes. The number of international students electing to 1 | P a g e 
complete their schooling in South Africa is constantly increasing, mainly because this might enable them to gain entry into oversubscribed local tertiary institutions. Parents are also attracted to the perceived high education standard, the option of international examinations and the discipline at South African schools, which are not often found at such affordable fee levels in other English-speaking countries (Hofmeyr \& Lee, 2008: 162).

Consequently, many well-to-do parents, particularly from other African countries, opt to send their teenage children to English independent secondary schools in South Africa to give their children the "best possible education" (Spaull, 2015: 14). Kamwangamalu (2013) observed that the English language was seen by various Africans, even in Francophone countries, to be a symbolic gateway to a better life. Affluent parents naturally want their children to have what they believe to be the best chances possible, and they are prepared to pay the premium rates charged by schools that offer the opportunity of upward mobility. After all, "children inherit the social station of their parents, irrespective of their own motivation or ability" (Spaull, 2015: 14).

Predominantly for emotional and financial reasons, many parents delay moving their secondary school children to a new school in a new country to the beginning of their Grade 10 year or even later, which significantly increases the academic burden on these students. English, the new language of teaching and learning, might be their third or even fourth language, which they only really start learning in their teenage years.

International students with language barriers who enter the education system only at secondary and senior secondary level create serious challenges for the schools that accept them. Research suggests that international students need five to seven years to acquire proficiency in a new language (Lemmer, Meier \& Van Wyk, 2006: 54); therefore, the language acquisition process has to be accelerated dramatically for these students to reach their educational goals.

\subsection{Typical challenges for international students with language barriers}

As is the case globally, students with language barriers entering the South African independent school system at secondary level might face major difficulties in acquiring academic English while simultaneously succeeding academically and socially in school.

$2 \mid \mathrm{P}$ a g e 
Lucas (1997) observed that international learners entering American secondary schools with limited proficiency in English had to negotiate a series of critical and challenging transitions daily. Whilst they were dealing with the difficult developmental passage from childhood to adolescence to adulthood, they also had to make the transitions from their native country to the new country and from primary to secondary school (Lucas, 1997: xiii). For most of these students, this was their first experience of boarding school and of being so far from home. Apart from culture shock, many other factors could affect international students' adjustment to schooling in a different country, as well as their simultaneous transition from early to late adolescence. These include individual and family characteristics, similarities and differences between their native countries and cultures and those of the new one, their entire relocation experience, and the context within which they lived previously (Lucas, 1997: xiii).

Secondary students must master the advanced level of academic content, as well as the sophisticated general and academic vocabulary required to finish secondary school with marks high enough to gain entry into a South African tertiary institution. They need to do well in subjects that require a deep understanding of complex levels of English academic language, such as chemistry, physical science, mathematics, economics and geometry. "Most secondary school texts and materials involve a high level of English reading and comprehension ability" (Menken, 2013: 441). Students from certain countries may not possess strong academic language and literacy skills in their home language, and secondary schools are typically illequipped to teach both content and language (Menken, 2013: 452). Few schools can afford to provide specialised English language instruction that provides content at a level of English appropriate for individual students' level of language proficiency.

Menken (2013: 444) observed that, although many secondary school teachers still regarded basic literacy instruction as a task for primary school teachers and felt that this type of tuition was too easy and remedial for instruction at secondary level, there was growing awareness in education circles that academic literacy teaching across subject areas should become a normal part of secondary school curricula and teaching. Too many typical secondary school programmes, however, still assumed that students already had strong literacy skills and thereby excluded those who did not.

The language skills students need for normal social interaction are vastly different from those required to function in a formal academic classroom. Academic language use includes not only $\mathbf{3} \mid \mathrm{P}$ a g e 
specialised vocabulary, but also special forms of expression related to the specific academic domains (Kaiser, Reynecke \& Uys, 2010: 57). Skutnabb-Kangas and Toukomaa (1976) observed how English language learners could appear to educators to be superficially bilingual, for example when using language for social purposes, while still performing well below par on academic skills and tasks.

Cummins $(1980,2008)$ drew the important distinction between basic interpersonal communication skills (BICS) and cognitive academic language proficiency skills (CALP). BICS involves contextualised language supported by paralinguistic clues, such as hand gestures, facial expressions and register, as well as other situational and interpersonal signposts which create meaning. CALP, by contrast, is often more abstract with limited additional cues. Students require CALP to successfully complete schoolwork and assessments like those described in the previous paragraphs. Unfortunately, students typically learn BICS much more rapidly than CALP (Menken, 2013: 444).

Colombi and Schleppegrell (2002: 1) note that secondary students must acquire what they term "advanced literacy", which they define as:

The kind of meaning-making that is typical of secondary and postsecondary schooling and that is also required for participating in many of the professional, technical, bureaucratic, and social institutions of our world. We focus particularly on the education contexts, where students have to work in content areas that have particular ways of making meaning. Students' learning of disciplinary knowledge requires participation in social contexts where texts are actively constructed. Students need to be able to participate in literacy in ways that enable them to contribute to the evolution of knowledge. Failing to ensure that secondary students acquire advanced literacy is tantamount to denying them opportunities for full participation in school and later life.

Rather than being academically equal and homogeneous, students arrive in secondary school with widely contrasting levels of academic language and literacy skill competencies, subject knowledge and prior experiences in education (Menken, 2013: 444). Short and Fitzsimmons (2007: 6) aptly call the current situation "an academic literacy crisis amongst these students at secondary level."

$4 \mid \mathrm{P}$ a g e 
The rest of the article describes how three independent secondary schools are dealing with the situation described above. After a brief description of the research methodology, the following section provides general background on the research sites. This is followed by a detailed account of current educational practices employed by the three schools to accommodate these learners.

\section{Methodology}

The central aim of the overarching study was to determine what affordances CLIL (content and language integrated learning) models in European schools could create for language support to international learners in high-fee, independent schools in South Africa. This article attempts to answer the first subsidiary question, namely, how some of these schools currently conceptualise support for international students with language barriers.

Data were collected from the research sites using three methods. Firstly, and most importantly, self-report was used by means of individual semi-structured interviews with three selected key members of management at the research sites. Secondly, empirical data were gathered from each school regarding the number of international students at these institutions over the past four years. Finally, archival resources like yearbooks and school welcome packs were used to build a more comprehensive picture of the current practices at these sites.

A literature study of available literature on CLIL in Europe provided a comprehensive conceptual map of potentially relevant factors to the South African independent school context. Using this map as a basis, a set of questions was developed for the semi-structured interview schedule. To place the study squarely within the qualitative realm, the number of interviewees was limited so that the face-to-face interviews could be reported on in richly woven, dense detail. Only the principal and two other senior staff members directly responsible for the conceptualisation of language support at the identified research sites were approached. Although this top-down view had negative aspects, input from the actual 'engine room' was vital to create a baseline of knowledge. An obvious disadvantage was that data would not be gathered from teachers tasked with the actual implementation of these measures. There was also no way of determining how effective these measures were from the students' point of view.

$\mathbf{5} \mid \mathrm{P}$ a g e 
The interpretive paradigm was used for this qualitative study. As Le Grange (2000: 193) explains, this paradigm embodies "fluid versus static reality; subjectivity versus objectivity; insider's perspective versus outsider's perspective; emergent categories versus fixed categories; and understanding versus explanation." Conceptual analysis, factual data analysis and teacher interviews formed the units of analysis for the research.

\subsection{The research sites}

International students with language barriers may find it challenging to compete on an equal footing with local students with regard to sitting entrance examinations for independent secondary schools. For this reason, these students gravitate towards schools without stringent entrance tests in place. Consequently, this study focussed on independent schools in the Western Cape without rigorous admission policies. During the period of January to May 2017, there were only three high-fee independent schools in the Western Cape with more than 300 secondary school pupils that did not clearly indicate on their websites that they had formal, exclusionary entrance examinations in place.

It was therefore a logical course of action to choose these three schools, which seemed to offer relatively easy access to international students, for this research. Two of the three schools were boarding schools, one in the heart of Cape Town and one in a rural area close to Cape Town. The third school did not need a boarding facility as it was situated in a rapidly developing area of Cape Town.

School A, an independent school of roughly 20 years old, is approximately an hour's drive from Cape Town. The vast grounds are immaculate, and an AstroTurf hockey field has pride of place amongst the various sports fields and facilities. The steady influx of international students to the school over the past few years has contributed significantly to the school's continued growth.

School B, an independent boarding school in an urban area, has long been known in education circles to have a large international learner base. At nearly 50 years old, School B is more than double the age of the other two schools in the study, although its transition from being a cram school to a traditional one is fairly recent. While the school buildings are beautiful and well-

6|P a g e 
maintained, School B has a slight inner-city school feel about it and the buildings front onto a busy city street. Students do not wear school uniforms and there are no bells, intercoms or organised sport.

School C's brand-new buildings on a vast tract of land seem to indicate that the school is set on aggressive future development. At 20 years old, this young, high-fee private school is about the same age as School A, but without a boarding facility. School C's geographical location in the heart of a rapidly developing, well-to-do area makes a boarding facility redundant. In recent years, the school has become known for its competitive edge and focus on academic excellence. Like School A, this school has also maintained a $100 \%$ pass rate since its first group of Grade 12 s graduated in 2000 . According to their updated website in 2018, there had been a change in policy since the start of the study. School $\mathrm{C}$ became the only one of my research sites with formal, exclusionary entrance tests in place.

Along with the principal, two other senior members of staff who dealt extensively with issues relating to international students were interviewed. At School A, one staff member identified was an educational psychologist who was also the head of the ESU (Educational Support Unit) at the school. The information provided in the rest of the article came from the transcripts of these interviews, as well as from data provided by the three sites.

\subsection{The data}

Even though, unlike School B, School A did not specialise in this market segment, data surprisingly showed a larger percentage of international learners at School A than at School B. More than a quarter (27\%) of School A's students did not have English as a home language, whereas almost a fifth (18\%) of students at the school had international passports.

At Schools B and C, the percentages of non-mother-tongue speakers were $22 \%$ and $11 \%$ respectively, while a full quarter of students at School B held international passports, compared to the $10 \%$ at School C. It seemed clear from the above data that, in the words of School A's principal, “... boarding just opens your international gates more than day schools can.”

It is worth noting that, at all three sites, data compiled excluded students with Afrikaans as a first language. When asked about this, the reason given was that Afrikaans students had become $7 \mid \mathrm{P}$ a g e 
assimilated to such an extent that it would be almost impossible to identify them without individual interviews. Due to the fact that Afrikaans students did not fall within the parameters of the study, this issue was not pursued at the time.

Table 1: Summary of data provided by participating schools

\begin{tabular}{|l|l|l|l|}
\hline January 2018 & School A & School B & School C \\
\hline Total number of pupils in secondary school & 360 & 313 & 528 \\
\hline Number of boarders (if applicable) & $34 \%$ & $17 \%$ & Not applicable \\
\hline $\begin{array}{l}\text { Number of students for whom English is not their home } \\
\text { language }\end{array}$ & $27 \%$ & $22 \%$ & $11 \%$ \\
\hline $\begin{array}{l}\text { Number of students with international passports } \\
\text { Number of students with international passports in } \\
\text { boarding }\end{array}$ & $13 \%$ & $25 \%$ & $10 \%$ \\
\hline $\begin{array}{l}\text { Number of international students on exchange (for up to } \\
\text { one year) }\end{array}$ & $4.5 \%$ & 0 & Not applicable \\
\hline
\end{tabular}

As can be seen in the table, whereas School B's overall numbers had dropped by $10 \%$ between 2014 and 2018, School A's numbers had increased. Despite its remote location, the struggling national economy and high fees, the secondary section of School A school managed to grow by $13.5 \%$ during this time.

The data seemed to demonstrate that both Schools A and B had become schools of choice for international learners, both with and without language barriers, and thus innovators in this fastdeveloping market segment. Their success in attracting these students made their methods deserving of closer scrutiny.

\section{Current educational practices related to international students at the research sites}

\subsection{The role of international students in the schools' strategic development plans}

At School B, international students had always been a part of the school's vision and, according to the principal, they typically catered for at least 20 nationalities per year. With between $20 \%$ and $25 \%$ of the student body being international, the principal felt that there was no minority at the school, and that "this fact worked well for everyone." Yet there had been a significant drop in student numbers at School B over the last few years. Due to this reality, their strategic 
plan had to be adapted. As a result, School B, which had always catered solely for the FET band (Grades 10-12), opened up Grade 8 and 9 classes for the first time in 2018 to increase enrolment.

According to the principal of School A, international students had become a major part of the school's future strategic plans relatively recently. Yet he believed that every student, no matter where he or she came from, benefited from being exposed to different ways of thinking.

The prevailing sentiment at School C differed starkly from that of the other two schools. The interviewees at School C were emphatic that international students with language barriers were not a part of their future growth plans. They felt that these students put additional strain on the infrastructure of the school. Not only did they have to acquire English at an accelerated rate, but they often had to study Afrikaans as a second language as well.

However, all the interviewees at all three schools agreed that, for various reasons, it had recently become extremely difficult for parents from other African countries to bring money to South Africa to pay for their children's education. The amount of debt given in good faith by these schools could become staggeringly high due to delays in payment, and this fact had ramifications for the schools' cash flow. Another common problem was the increased difficulty for these students to get educational visas for South Africa.

\subsection{Entrance requirements and procedures}

With more than a quarter of the school's students not being mother-tongue English speakers, it was natural to assume that the entrance procedures at School A would run like a well-oiled machine. This was, surprisingly, not the case. There also seemed to be a significant gap between the perception of the members of staff interviewed and that of their principal about the exact procedures followed with prospective applicants.

According to the principal of School A, admission procedures at the school were well-defined. Applicant interviews were often done on Skype. He usually informed these students that they would only do a proper entrance test once they arrived at the school for the new academic year. This assessment would only be a diagnostic tool and not an entrance test - "a way to see where the individual would need help." The school also conducted a separate test for mathematics 9|P a g e 
because, "if you have a lot of repair work to do you have to know what you are taking on." Students with language barriers were not expected to adhere to a definite time frame, but "we just try to keep the conversation going," the principal added.

The other two senior staff members at School A, however, did not experience the existing entrance procedures as clear-cut. They seemed to feel that not all new students completed the entrance tests, and that students would sometimes apply to the head of marketing, be accepted and arrive in January without any prior involvement from the school's side. Both teachers seemed to feel that School A was now at a point where formalised processes around admission had become vitally important and that a designated person should be appointed to regulate procedures. They also felt that more could be done from management's side to streamline and manage the admission process to make it less "traumatic for teachers", as one of the interviewees expressed herself. Both agreed that formal language screening procedures should be put in place as a matter of urgency, and that a student should not be able to arrive on campus knowing little or no English. Entrance tests needed to be administered in an organised fashion if the school wanted to deal with these learners more effectively. If teachers were made aware of the exact language proficiency level of the student beforehand, planning by all concerned could be done much more efficiently.

The head of the ESU at School A also felt that allowances should be made beforehand for funds that might be needed at a later stage for interventions like language schools, psychiatrists, medical needs and so on. If, once these students were at the school already, much-needed interventions could not be put in place because of a lack of funds, teachers could feel frustrated and helpless because the student was not functioning optimally. (At the time of the interviews, School C already required international students to provide a full term's tuition in advance to be held for contingencies. A similar arrangement at School A could potentially alleviate the situation.) The educational psychologist added that the school should make a conscious effort to inform parents, as well as students, beforehand that certain non-negotiable systems had to be established to make this experience a successful one for everyone concerned. A relevant example, according to her, would be a contract between the family and the school which clearly set out what the student, as well as the family, expected from the experience. An honest academic and psychological history of the child should form a non-negotiable part of such a contract. Both teachers also felt that students with language barriers should ideally not be

$\mathbf{1 0} \mid \mathrm{P}$ a g e 
entering the school only at Grade 10 level or later, and definitely not without first completing an extensive bridging course.

Entrance tests in mathematics and English were introduced for the first time at School B in 2018, not to exclude anyone but merely as a diagnostic baseline assessment. "Because of the school's value proposition, there would always be an incremental improvement in the students' achievement, even after a relatively short space of time," the principal said. Their mark-reading system of eight detailed progress reports, spread throughout the year, was an important intervention mechanism. By August of any given year, a student would have received six markreadings. These reports went a long way towards dispelling false expectations on all sides.

School B was the sole school that readily accepted new students in Grade 12. In 2017, they had 60 new students in Grade 12, and they all passed at the end of the year. The principal believed that this was "unheard of. I don't think there is any other school who can do that." Ironically, this aspect seemed to provide a bulwark against homesickness and depression for new students. The fact that up to one third of the student body could be new to the school in any given year ensured that "you are not the only one; your countrymen and -women are also here," the principal felt.

School C preferred a face-to-face interview with prospective students to using Skype, largely because students also had to do the prerequisite written testing. On the rare occasion where a physical meeting proved to be impossible, an online assessment would be done. Prospective students' ability in mathematics and English was thoroughly tested before they were accepted to the school. If smaller issues emerged from the testing, students were placed on a conditional. This conditional acceptance was usually valid for six months only and various structures, such as sessions with the English as a foreign language (EFL) teacher, were put in place to assist these students.

School C did not accept any new students in Grade 12, especially not students with language barriers. The school was also reluctant to accept new students into Grades 10 and 11, but they accepted the fact that South-Korean students often only arrived in the country at this stage. Students applying to enter the school at Grade 10 level would write the entrance examination and get flagged immediately if there was a language problem. Nevertheless, problems would

11 | P a g e 
occasionally only become apparent after students entered the school. These issues were then addressed immediately.

As was the case at School A, the two counsellors on School C's campus were very involved with foreign-language students. "Often we find that, with the Asian students, their culture is vastly different and there is a lot of pressure on these students to perform," the head of English said. Counsellors kept a close eye on these students, especially those who were living away from their parents, and communicated with the parents when the need arose.

\subsection{Teacher allocation}

All three schools had a part-time EFL teacher on site. This intervention usually happened on a one-on-one basis, although there could be up to three students in a group. Students met the EFL teacher once a week for an hour, mostly to work on English language skills.

Interviewees seemed to agree that some teachers were naturally better with foreign-language speakers, whereas others were not as well attuned to the needs of these students. At School B, a student was free to move to another class if a teacher's specific teaching style was not helpful to the student.

\subsection{Interventions}

This section describes the interventions already present in these schools to support international students with language barriers. It was notable that the interventions were mostly whole-school interventions that benefited all students in the school. They also did not require an additional layout of capital.

\section{Subject choices and streaming (grouping according to ability)}

At School A, there was no official streaming in English, although it had been happening unofficially to some extent. The school also recently brought in CAT (Computer Application Technology) as a subject option against Afrikaans to accommodate international students who were exempt from doing Afrikaans as a second language. Surprisingly, the school did not offer
Commented [11]: Please check whether you want to retain "foreign-language" here. Where the substitution seemed natural, I replaced "foreign-language students" with "international students with language barriers" because that is the term used in the title of the article.
Commented [12]: Please check whether you want to retain "foreign-language" here. Where the substitution seemed natural, I replaced "foreign-language students" with "international students with language barriers" because that is the term used in the title of the article. 
design or tourism as subjects, even though both subjects are generally accepted to be manageable subjects for international students with language barriers.

At School B, students could choose any combination of subjects, although there was a fixed timetable. By the end of the day, a student might have shared a classroom with up to 80 other students, although there were never more than 20 students in a class. According to the deputy who did the timetabling at the school, School B started streaming English classes in 2016. At that time, staff felt that change was warranted because the top students were not being sufficiently extended and the weaker students were not being reached. At the time of the interview, there was one class per grade with predominantly international students, with weaker local students also included. This enabled the teacher to pitch at a specific level for a specific group. The deputy was adamant that streaming in English and mathematics just "works better". The principal of School B was justifiably proud of the fact that they had never had any failures in English at Grade 12 level.

In Grades 10 to 12 at School C, mathematics, science and English were streamed. Remarkably, students in Grade 9 were separated according to gender for English and mathematics. According to the head of English, research ostensibly showed that this system worked very well for this age group and the school had been doing it this way "forever". The interviewees had found that girls particularly flourished in this situation because they were usually more mature than boys at that age. There was also a system of master classes. When a new topic was introduced in a subject area or when a grade started a new project, the whole group would typically meet in the auditorium for one or more introductory sessions before reverting to smaller groups.

\section{Tutorials and extra classes}

At School A, there were two weekly double lessons where struggling international students were taught in a group, with a focus on communicative English. Tutors were employed when needed for the parents' account and teachers provided additional support where possible. Some students in the boarding house occasionally clubbed together for a tutor, often one who could teach them in their first language.

$\mathbf{1 3} \mid \mathrm{P}$ a g e 
A useful tool in School B's toolbox was the 50-minute homework consultation lesson at the end of each school day. This session provided students with the opportunity to consult teachers daily on a one-on-one basis. When it came to English acquisition, the female deputy at School B felt that everyone had their specific way of getting things done, stating that, "obviously, everyone's overriding concern is English."

At School C, teachers were expected to offer tutorials after school as part of their job description. Taiwanese and Chinese students often had their own tutors who worked with them in their first language. According to the principal, they provided no sheltered situation to cushion international students when they arrived, adding, "immersion is the key. We want to treat everyone on the same level."

\section{Additional reporting}

School A had systems in place to alert parents timeously to possible issues. These systems included putting students on a daily report system, as well as a midterm reporting process similar to School B's mark-reading system.

As mentioned, the most successful arrow in School B's quiver seemed to be their mark-reading system, a midterm reporting system. The school had eight reporting cycles per year. Due to these additional midterm reports, everyone involved with a student's progress was forced to take stock more frequently. The first report was in February, and picked up potential problems early. When these reports showed that the language issue was larger than anticipated, the necessary steps could be put in place sooner rather than later.

\section{Language schools}

The principals of Schools A and B had differing views about language schools. School A's principal found that, although particularly Portuguese families from Angola were quite open to the idea of sending students to a language school before arrival, he was not convinced that this type of intervention was optimally beneficial. "It may improve their speaking and writing somewhat, but it is not nearly enough to put them on par with other students."

$\mathbf{1 4} \mid \mathrm{P}$ a g e 
At School B, it was accepted practice to send struggling students, especially Korean students, to a language school for a full school term. Students also sometimes came to them via a language school. In contrast to the view expressed by the principal of School A, the principal of School B felt that a stint at a language school often addressed many issues, and that a partnership with a language school was important over the long term.

\section{Other interventions}

Many subject teachers at School B were already making a conscious effort to explain new terms as they occurred, even if most students were familiar with these terms. The interviewees agreed that the language teachers could not take sole responsibility for subject-specific vocabulary.

The deputy at School B felt that they could also create more dictionaries like the mathematics dictionaries they had already created for mostly Angolan and Mozambican students. The problem with developing dictionaries, however, was that the student population shifted. They may have had many Portuguese students at this point, but in the future, for example, they might have more Swahili students.

\subsection{Additional socio-cultural factors}

In the interviewees' experience, additional socio-cultural factors also contributed to student success or failure. Being aware of these area-specific tendencies could help schools to further refine their offering. The fact that students from certain countries often had similar issues is discussed under the first subheading. School B's students were often older than 18, and this led to certain challenges. School A's large exchange student population, in turn, brought its own difficulties.

\section{Countries of origin}

A common thread that emerged from the interviews was the perception that students from certain African countries, mainly Angola, Mozambique and the DRC, often battled with the acquisition of English because of poor teaching of their first language in their primary school years. It is widely believed in education circles that key concepts are common across different languages and therefore have the potential to be transferred from a first language to a second-

$15 \mid \mathrm{P}$ a g e 
language education context. This theory is known as the "interdependence hypothesis" or the "iceberg effect" (Cummins, 1980: 179). A keystone of the interdependence hypothesis is that the student must have reached a certain competence threshold in his or her new language before the transfer from the first to the second language can take place. Even though some of these students may have basic conversational skills in English, the linguistic building blocks which were supposed to be put in place while learning their first language might be missing and can therefore not be transferred successfully from one language to another.

In the case of learners from China, a common thread which recurred in the interviews was the observation that the so-called 'parachute kids' often struggled more than other international students to cope, mainly due to a lack of parental support. Parachute kids were typically sent to a foreign country on their own to complete their schooling. They were often very young, even 12 to 13 years of age, and found themselves completely overwhelmed by how alien everything was in the new country. As a result, many of these students found themselves unable to cope emotionally and intellectually. Chinese students frequently came to South Africa via an agent and were accommodated in a flat by themselves or ended up living with a guardian who was paid a fee. They also tended to keep themselves apart from other students and this, according to the interviewees, did not allow the vital process of immersion to happen.

Age

Twenty percent of the current Grade 12 group at School B was over 18 years of age. This older cohort habitually arrived at the school with clear goals set, as they had taken ownership of their academic future. School B was unique in that it accepted students up to the age of 27, even though there had been some resistance from the Western Cape Education Department. Many students, especially those from Angola and Mozambique, had typically already finished their schooling in their own countries and, in some cases, even worked for a year or two. They were typically 21 or 22 years old and highly motivated. The only problem, according to the deputy at the school, was that they all wanted to study engineering at tertiary level. Sadly, these students were usually only required to do either physics or chemistry as a subject in their countries of origin, hence they had to catch up on the other one when they arrived at School B. The school recommended strongly to these students that they repeat both Grades 11 and 12 instead of just Grade 12. This initiative had been so effective that they were thinking of making this arrangement compulsory.

$\mathbf{1 6} \mid \mathrm{P}$ a g e
Commented [13]: Please check whether you want to retain "foreign" here, or whether you perhaps want to change "a foreign country" to "another country" 


\section{Transience}

School A received many short-term exchange students, mostly from Europe, who could spend anything from three months to a year at the school. The principal felt that these students were usually industrious and sophisticated, and that they generally bolstered the school's sport, especially hockey. In 2018, however, the German contingent had been bigger than ever before, "two and a half times the usual amount, to be exact," he stated. International exchange students at School A made up $4.5 \%$ of the school's population in this year. For the first time the school had experienced the problem of students speaking German to each other in the passages. Due to the sheer number of short-term boarders, the typical integration with other boarders and day students did not occur. The principal admitted that the school had been caught on the back foot with no formal structures and policies in place. Help from members of the English department staff alone had become insufficient because they were spread too thin. When frustrated international students approached the educational psychologists, they had been referred to the remedial teachers. Everyone had ended up assisting in isolation because there was no proper system in place. The two staff members interviewed were adamant that systems had to be put in place to prevent this situation from happening again. Planning for the next year had already begun.

\section{Discussion}

Hofmeyr and Lee wrote as early as 2008 that:

... there are now a myriad of new, high-fee independent schools all fishing in the same, high-income earning pond, which has not grown at the same rate. While increased, mainly white emigration has sunk the pond considerably, the growing black elite, often referred to as black diamonds, are not increasing as fast as the schools have been (Hofmeyr \& Lee, 2008:13).

Consequently, the competition between independent schools at the upper end is fiercer than ever, and newer and less well-established second-tier schools are often not full. Many of the latter had to borrow extensively to provide the essential 'private school' infrastructure and, as a result, find themselves exposed to negative market forces in the post-euphoric first decades $\mathbf{1 7} \mid \mathrm{P}$ a g e 
of the $21^{\text {st }}$ century. One way of attracting more 'fee-paying clients' is lowering entrance requirements.

Without entrance screening in place to fulfil a gatekeeping function, almost any student with limited linguistic competency whose family can afford to pay the school fees, can gain access to supposedly hallowed halls of learning. In stark economic terms, the situation can be viewed as an educational transaction where there is a willing buyer (the parent) and a willing seller (the school). A direct result of this commercial transaction is that secondary classrooms could become multilevel teaching spaces, yet teachers have no access to the traditional support systems and training normally available to teachers in a similar situation. Another possible result of this transaction is that the student being 'transacted' could refuse to take ownership of his or her immediate academic future, due to a perceived lack of agency. This refusal to take ownership could lead to rebellious acting out and other disciplinary infringements by the student. It could also lead to severe depression and other mental problems amongst these students.

It became clear from the interviews that measures which had already been put in place by these schools to accommodate these international students with language barriers were within the confines of their mainstream schooling infrastructure, probably to limit additional costs. Existing staff at the research sites were, in most cases, expected to absorb the additional teaching responsibility for these students within mainstream classrooms with little or no organised, institutional assistance.

All interviewees agreed that having a full-time EFL teacher on board would be an immediate, significant improvement. This teacher could float and target specific students in certain grades. The teacher would pick up specific information in the process, for example that a certain student needed specific help with mathematics vocabulary.

Although both Schools A and B claimed that international students formed a significant part of their future strategic plans, there were no official guidelines from either management or overarching bodies in place to assist teachers at these schools. The head of the ESU at School A felt that, as a matter of urgency, someone at the school needed to be tasked with clarifying and structuring processes concerning the admission and integration of learners. The head of English at the same school had a more ambitious vision for the future. She believed that the $\mathbf{1 8} \mid \mathrm{P}$ a g e 
ideal future scenario at the school would be a separate, sheltered teaching unit where international students could initially study until they were ready to join the mainstream, instead of attending normal classes. Like the interviewees at School B, she also felt that the perfect scenario would include a dedicated teacher who communicated about all the subjects with teachers and who looked at the holistic picture of a student's progress.

More discussion amongst staff members and a united approach to accommodating these students would also go a long way towards addressing problems. Teachers need to talk openly about the things with which they are struggling. Schools could even discuss different approaches within the Independent Examination Board or Western Cape Education Department clusters and pool ideas and resources. The head of the ESU at School A noted that change was already afoot, and that Eurocentric approaches and assimilation were no longer optimal at the school. Everyone was becoming more aware of different cultures.

Over the short term, the principal of School A planned to provide more training for teachers at the school. He believed that local students needed to learn another language to learn to understand other cultures. This exposure could break down this pervasive sense of "this is how we do things and you have to come in here and learn how to do things our way." Students had to learn to understand that everyone could add something to make a difference and that there was no such thing as normal. Yet firstly, "the light had to go on." People had to start thinking about what these international students went through in the school's culture, he continued. They had to think, for example, about the names of the school's houses or about the school song that was sung during assembly. He understood that even something as seemingly insignificant and benign as mispronouncing a surname could make a student feel excluded.

\section{Conclusion}

Although the last Independent Schools Association of Southern Africa benchmarking survey, conducted in 2003, indicated that $5.2 \%$ of students in SA independent schools were international, data from this study could indicate that the percentage of international learners in new, high-fee independent schools might be significantly higher than that figure, especially in the case of boarding schools. However, because the study was limited to three younger, highfee independent schools in the Western Cape that did not clearly state that they had an entrance

$19 \mid \mathrm{P}$ a g e 
examination on their websites in 2017 , it might be risky to apply these data to the wider independent school sector in South Africa without extensively qualifying the data.

While the article's primary aim was to establish a knowledge base of how three high-fee independent secondary schools in the Western Cape currently conceptualise language support for international students with language barriers, it also attempted to provide a glance at possible cracks in the well-maintained façades that the principals of these research sites, which are essentially education businesses, tried to present at the time.

Pam Christie's (1990: 122) supposition that, when a critical mass (35\%) of black enrolments was reached at a previously white institution in South Africa, a whole different set of dynamics would come into play, resonated strongly with the researcher, who was curious to see if this statement held true when the critical mass of non-mother-tongue English speakers, white and/or black, South African or international, came close to $35 \%$ in a traditionally homogeneous English institution. Merely adding a conservative estimate of $10 \%$ of Afrikaans-speaking students to the $26.6 \%$ of other second-language speakers at School A in 2018 would place the number of non-mother-tongue English speakers at the school above Christie's (1990) 35\% mark. Using Christie's lens, it was thus not surprising that School A's principal felt that "things reached a sort of crisis point" in 2018. He admitted that things changed sharply and radically when the number of international students with language barriers increased sharply. The state of benign assimilationism, which, according to Soudien (2004: 105), was evident in most former white English schools in South Africa, had to change.

The winds of change indeed seemed to be blowing. "As the percentage of international students grew", the principal of School A concluded, "there has been more of a realisation that this is only going to keep growing, it is not going to get smaller. If we keep doing things the same old way, it is not going to be as effective or things are going to be more tense than they need to be." This statement resonated strongly with the researcher's own view that there has to be a more effective way of dealing with these students.

In the follow-up article, the researcher will argue that a CLIL (content and language integrated learning) model could greatly enhance not only the quality of teaching, but also the rate of language acquisition for international students with language barriers at these sites.

$\mathbf{2 0 | P}$ a g e 
Kaiser, Reyneke and Uys (2010) recognised the possibilities that the CLIL model offers for mainstream education in South Africa a decade ago. The fact that language is not merely a challenge in bilingual education or for students with migrant or other second-language backgrounds, but for any pupil, makes the CLIL model viable for these schools, not only in a sheltered situation for international or second-language students, but also in a mainstream context.

\section{Bibliography}

Christie, P. 1990. Open schools: racially mixed Catholic schools in South Africa, 1976-1986. Johannesburg: Ravan.

Colombi, M.C. \& Schleppegrell, M.J. 2002. Theory and practice in the development of advanced literacy. In: Schleppegrell, M.J. \& Colombi, M.C. Eds. 2002. Developing advanced literacy in first and second languages: meaning with power. New York: Erlbaum. pp. 1-19.

Cummins, J. 1980. The cross-lingual dimensions of language proficiency: implications for bilingual education and the optimal age issue. TESOL Quarterly 14(2):175-187.

Cummins, J. 2008. BICS and CALP: empirical and theoretical status of the distinction. In Hornberger, N.H. Ed. 2008. Encyclopedia of language and education. Boston: Springer.

Hofmeyr, J. \& Lee, S. 2008. The new face of private schooling. Updated version, received from author by email, of: Hofmeyr, J. \& Lee, S. 2004. The new face of private schooling. In Chisholm, L. Ed. Changing class: Education and social change in post-apartheid South Africa. Pretoria: Human Science Research Council. pp. 143-174.

Kaiser, K., Reynecke, M. \& Uys, M. 2010. Eating soup with a fork: why the EFAL syllabus cannot promote learning across the curriculum. Journal for Language Teaching 44(2):5267.

Kamwangamalu, N. 2013. Multilingualism in South Africa. In: Bhatia, T.K. \& Richards, W.C. Eds. 2013. The handbook of bilingualism \& multilingualism. $2^{\text {nd }}$ ed. Malden: Blackwell. pp. 791-812.

Le Grange, L. 2009. Educational research 769. Unpublished study guide for BEd Hons, University of Stellenbosch.

Lemmer, E.M., Meier, C. \& Van Wyk, N. 2006. Multicultural education: an educator's manual. Pretoria: Van Schaik.
Commented [14]: Deleted three sources that are no longer cited in the text. 
Lucas, T. 1997. Into, through, and beyond secondary school: critical transitions for immigrant youths. Washington, DC: Center for Applied Linguistics.

Menken, K. 2013. Emergent bilingual students in secondary school: along the academic language and literacy continuum. Language Teaching 46(4):438-476.

Short, D. \& Fitzsimmons, S. 2007. Double the work: challenges and solutions to acquiring language and academic literacy for adolescent English language learners. Available: https://www.nwp.org/cs/public/download/nwp_file/9050/Double_the_Work.pdf?xr=pcfile_d [Accessed: 3 February 2020].

Skutnabb-Kangas, T. \& Toukomaa, P. 1976. Teaching migrant children's mother tongue and learning the language of the host country in the context of the socio-cultural situation of the migrant family. Tampere: University of Tampere.

Soudien, C. 2004. Constituting the class: an analysis of the process of 'integration' in South African schools. In: Chisholm, L. Ed. 2004. Changing class: education and social change in post-apartheid South Africa. Pretoria: Human Science Research Council. pp. 89-114.

Spaull. N. 2015. While the rich get education, SA's poor just get 'schooling'. Sunday Times, 8 November. 